\title{
IDENTIFICAÇÃO DA EXPANSÃO DA LAMA POR SUBTRAÇÃO SIMPLES DE BANDAS E ANÁLISE DE COMPONENTES PRINCIPAIS NA BARRAGEM DE SANTARÉM - MARIANA/MG
}

\author{
João Pedro dos Santos ${ }^{(a)}$, Helder Lages Jardim ${ }^{(b)}$ \\ (a) Graduando em Geografia do Departamento de Geografia / Instituto de Geociências, UFMG, \\ joaopedrosgeo@gmail.com \\ (b) Professor Adjunto do Departamento de Geografia / Instituto de Geociências, UFMG, \\ hljardim@gmail.com
}

\section{Eixo: GEOTECNOLOGIAS E MODELAGEM ESPACIAL EM GEOGRAFIA FÍSICA}

\begin{abstract}
Resumo
A mineração é uma atividade que causa grandes impactos ao meio ambiente. Em 2015 a barragem de rejeitos de Fundão (Mariana/MG) se rompeu causando o maior desastre ambiental de Minas Gerais fazendo com que a barragem de Santarém, a jusante, extrapolasse sedimentos. Os processamentos digitais de imagens são úteis para análises geoespaciais permitindo que sejam criados meios apurados para verificação de alterações em caso de desastres ambientais. Dentre os diversos processamentos diferentes podemos destacar dois: Subtração Simples de Bandas e Análise de Componentes Principais. Com isso, o objetivo desse trabalho é identificar a expansão da barragem de Santarém após o rompimento da barragem de Fundão utilizando as técnicas mencionadas. Foram processadas no programa SPRING imagens multiespectrais do satélite Landsat8 de antes e após o rompimento. Nas imagens resultantes da Subtração Simples de Bandas e da Análise dos Componentes Principais as áreas que apresentaram mudança são representadas pelos pixels de maior intensidade, portanto os mais claros. Os processamentos se mostraram úteis para análise rápida do acontecido.
\end{abstract}

Palavras chave: Sensoriamento Remoto, Imagens Multiespectrais, Mineração

\section{Introdução}

A mineração é uma atividade que causa grandes impactos ao meio ambiente. Ela pode interferir no relevo, hidrografia, fauna e flora. Seja pela grande movimentação de terra e caminhões ou pelas explosões, rebaixamento de lençóis freáticos, emissão de poeira, retirada da vegetação, afugentamento da fauna, dentre outros impactos, dependendo do tipo da mineração. O Brasil possui grande potencial minerador. $\mathrm{O}$ segmento apresenta 4\% do Produto Interno Bruto (PIB). Só a produção de minério de ferro é responsável por $82 \%$ das exportações no país (PORTAL DO BRASIL, 2014).

Uma das formas de se obter máximo aproveitamento de minérios extraídos é através do beneficiamento. Uma das estruturas utilizadas neste processo são as barragens de contenção de rejeitos. Elas são utilizadas 
para reter os resíduos produzidos no processo. Os rejeitos não possuem vantagens lucrativas, mas são altamente danosos ao meio ambiente e por isso são armazenados.

No Brasil há 663 barragens de rejeitos de mineração (PLATONOW, 2015). Boa parte desses rejeitos possuem granulometria fina sendo identificados como lama (ESPÓSITO, 2000). Devido ao potencial de danos ao meio ambiente o governo de Minas Gerais através da Fundação Estadual do Meio Ambiente (FEAM) realiza desde 2002 o Programa de Gestão de Barragens de Rejeitos e Resíduos com o objetivo de fiscalizar e realizar estudos sobre barragens. Em 2014 foram identificadas 450 barragens cadastradas na tipologia "mineração" em Minas Gerais. Ou seja, cerca de 68\% das barragens de rejeitos estão neste estado. Dado esse total e considerando as outras tipologias de barragens ("Indústria" e "Destilaria de Álcool") é possível apontar diversas dificuldades no controle e monitoramento pelos órgãos públicos como o número de físcais em relação aos empreendimentos e a estrutura para realizar os monitoramentos. Segmentos geradores de grandes impactos demandam fiscalização na instalação e na operação das atividades. Entretanto falhas ou a ausência de diligências podem facilitar a ocorrência de desastres ambientais oriundos destas atividades.

Em 2015 a barragem de contenção de rejeitos de Fundão pertencente à mineradora Samarco S/A se rompeu causando o maior desastre ambiental de Minas Gerais. O rompimento ocasionou o despejo de lama sobre cursos d'água sobre a barragem de Santarém onde, por sua vez, extrapolaram os sedimentos pela bacia hidrográfica do Rio Doce seguindo em direção leste passando por mais de quarenta municípios até o estado do Espírito Santo onde atingiu o Oceano Atlântico (IBAMA, 2015). Junto a esse se somam seis rompimentos por barragens de rejeitos registrados para o estado de Minas Gerais. O primeiro ocorreu em 1986 em Itabirito. O penúltimo foi em 2014 tendo uma barragem da Mina Retiro do Sapecado pertencente à empresa Herculano Mineração Ltda. se rompido. Em quase todos os rompimentos as principais consequências foram óbitos, obstrução de vias, assoreamento, degradação de cursos hídricos e da vegetação e comprometimento econômico das populações atingidas (FARIA, 2016).

Uma forma de analisar as alterações ocorridas em desastres ambientais é por meio da utilização de técnicas de geoprocessamento. Com o uso de variados procedimentos é possível que sejam produzidas novas informações sistematizadas podendo estabelecer a abrangência dos impactos afim de que se possa buscar a melhor forma de gerenciamento dos desastres.

No campo das geotecnologias está o sensoriamento remoto que teve grande avanço nos últimos anos. Os últimos satélites lançados apresentam em seus sensores de imageamento diversas características inovadoras com melhores resoluções permitindo mais precisão para diversos estudos (SAUSEN e 
LACRUZ, 2015). Os processamentos digitais de imagens (PDIs), inerentes nessa ciência, são úteis para análises geoespaciais permitindo que sejam criados meios apurados para verificação de alterações do espaço. Dentre os diversos processamentos diferentes podemos destacar dois: Subtração Simples de Bandas e Análise de Componentes Principais.

A Subtração Simples de Bandas geralmente é realizada com rasters de dois períodos diferentes como mostrado no estudo de detecção da expansão da barragem de Maravilhas II em Minas Gerais (ALBERTI e VICTORINE, 2015). Da mesma forma que a Análise de Componentes Principais que se mostra vantajosa, pois apresenta resultados sem necessidade de realização de correção atmosférica ou normalização radiométrica - procedimentos necessários na Subtração Simples de Bandas (CHAVEZ e MAC KINNON, 1994). Ambas as técnicas permitem rápida visualização sobre a área de estudo fornecendo informações iniciais para estudos mais aprofundados.

Com isso o objetivo desse trabalho é identificar a expansão da barragem de contenção de Santarém (Mariana/MG) após seu rompimento em novembro de 2015 utilizando duas técnicas de processamento digital de imagem: Subtração Simples de Bandas e Análise de Componentes Principais. Os resultados pretendem agregar informação relativa ao planejamento e manejo da tragédia que é de grande impacto socioambiental.

\section{Caracterização da área de estudos}

A barragem de contenção de rejeitos de Santarém se localiza no município de Mariana. O rompimento da barragem ocorreu no Córrego Santarém, um dos afluentes do Rio Gualaxo do Norte que deságua no Rio do Carmo que por sua vez deságua no Rio Doce.

A ocupação de Mariana teve seu início no século XVII, sobretudo devido atividades de exploração de pedras e minerais preciosos encontrados na época. A partir do século XX a exploração do minério de ferro se torna um chamariz por empresas internacionais do seguimento minerário. Hoje o município de Mariana possui $80 \%$ de seu PIB originado da mineração (IBGE, 2010). Com isso, é possível identificar a dependência econômica do município em relação ao segmento. As demais atividades econômicas da região perpassam por agricultura de subsistência, pecuária, silvicultura, dentre outras. Devido às construções do período barroco e por magníficas paisagens cênicas o turismo é outra atividade de grande impacto econômico para o local (SUPRAM ZM, 2014).

A cobertura litológica é constituída na maior parte da região por xistos. Nas áreas a montante do barramento são encontradas feições quartizíticas, assim como dolomitos, itabiritos e filitos representantes 


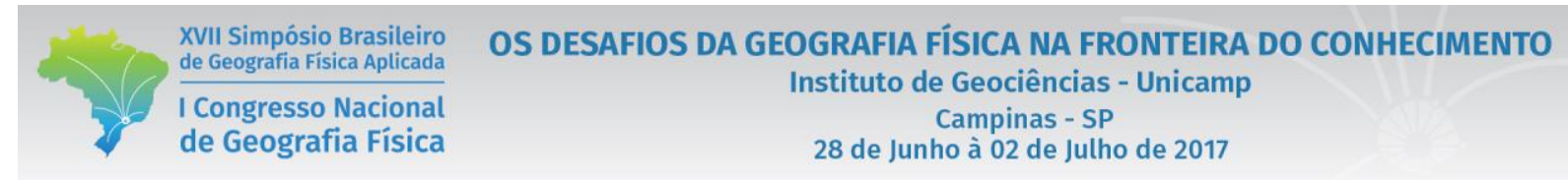

da unidade de topo do Supergurpo Minas e da Formação Santo Antônio do Grupo Itacolomi (CPRM, 2015).

Essa região possui cotas altimétricas com valores de grande variância. $O$ valor mais alto chega a aproximadamente $1350 \mathrm{~m}$ de altitude. Correlacionado principalmente à altimetria e sua localização latitudinal a divisão climática de Köppen desta área é a Cwa que corresponde ao clima temperado úmido com invernos secos e verões quentes. Segundo as Normais Climatológicas do Brasil 1961-1990 (INMET, 2016) a área de estudo se localiza na porção do país que possui pluviosidade anual média entre 220 e 260mm (INMET, 2016). A figura 1 mostra a localização da barragem.
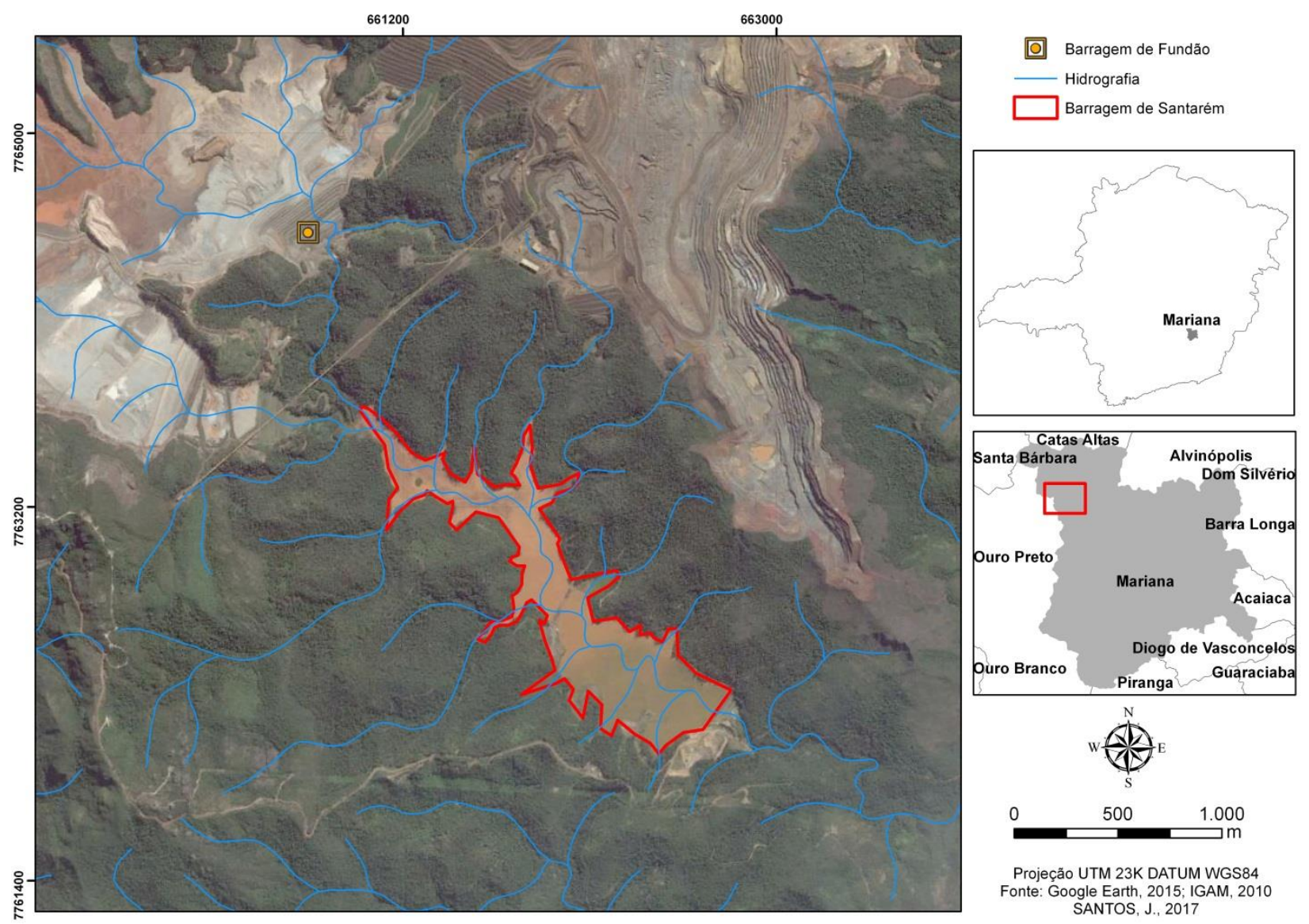

Figura 1: Localização da barragem de contenção de rejeitos de Santarém.

\section{Procedimentos metodológicos}

Todas as etapas foram acompanhadas por revisões bibliográficas contendo experiências práticas e empíricas relacionadas à temática. Após a definição do tema e dos objetivos os dados foram adquiridos e 
as ferramentas a serem utilizadas foram selecionadas. As imagens utilizadas são provenientes do satélite Landsat 8 e dispostas no acervo digital de imagens do INPE. A plataforma Landsat 8 opera com dois instrumentos imageadores: Operacional LandImager (OLI) - com as bandas 1 a 7 e 9 multiespectrais e a banda 8 pancromática - e Thermal Infrared Sensor (TIRS). Seu sensor OLI possui resolução espacial de $30 \mathrm{~m}$ nas bandas multiespectrais e de $15 \mathrm{~m}$ na banda pancromática. Sua resolução radiométrica é de 16 bits tendo seu período de revisita em 16 dias (USGS, 2015).

O primeiro conjunto de imagens utilizado data de 10 de outubro de 2015, um mês antes do rompimento da barragem aproximadamente. Já o segundo é de 16 de novembro de 2016, um ano após o rompimento aproximadamente. As imagens pertencem à Órbita-Ponto 217-74. Para este trabalho as bandas utilizadas serão: Banda 3 (verde), Banda 4 (vermelho) e Banda 4 (infravermelho próximo). Para processamento das imagens será utilizado o software de SIG SPRING na sua versão 5.3.

Na Subtração Simples de Bandas em imagens multiespectrais feições que apresentarem características diferentes serão realçadas. Alberti e Victorine (2015) apresentam recomendações de se utilizar imagens de condições próximas como geometria de iluminação e aquisição. Também é indicada a realização de correção atmosférica, para mitigação da influência da atmosfera sobre a cena.

Dessa forma, foram realizadas as correções atmosféricas seguindo o método Dark Object Subtraction proposto por Chavez (1988). O procedimento foi seguido pela normalização radiométrica de cada cena. Foi adotado o método de Uniformização das Médias e Variâncias (UMV) utilizando as imagens de 2016 como referência e as de 2015 como àquelas a serem ajustadas. Neste procedimento os níveis de cinza de cada banda são compatibilizados fazendo com que a associação temporal dos alvos seja possível. Com as imagens normalizadas foi realizado o processo de Subtração Simples de Bandas.

Com as imagens brutas foi executado a Análise dos Componentes Principais. A função transforma um conjunto de imagens (mesma banda com datas diferentes, por exemplo) em outro conjunto de imagens (CP1 e CP2). No primeiro Componente Principal (CP1) haverá as informações que são comuns aos conjuntos selecionados, já o segundo Componente Principal (CP2) haverá as feições espectrais relativas às alterações ocorridas (VARELLA, 2008). Esta função é vantajosa por apresentar resultados sem necessidade de realização de correção atmosférica ou normalização radiométrica (CHAVEZ e MAC KINNON, 1994).

Os resultados serão representados em imagens monocromáticas e em composições coloridas falsa cor com seus contrastes ampliados. Com as imagens dispostas será possível inferir algumas informações qualitativas a respeito dos momentos adquiridos. 
XVII Simpósio Brasileiro de Geografia Fisica Aplicada

I Congresso Nacional de Geografia Física
OS DESAFIOS DA GEOGRAFIA FÍSICA NA FRONTEIRA DO CONHECIMENTO

Instituto de Geociências - Unicamp

Campinas - SP

28 de Junho à 02 de Julho de 2017

\section{Resultados e discussões}

Os rasters resultantes das Subtrações Simples de Bandas são apresentados nas figuras 2, 3 e 4. As imagens correspondem às subtrações realizadas para as bandas dos canais verde, vermelho e infravermelho próximo, respectivamente. Na figura 7 está representada a composição colorida falsa cor $-345 \mathrm{BGR}-$ dado às imagens resultantes.

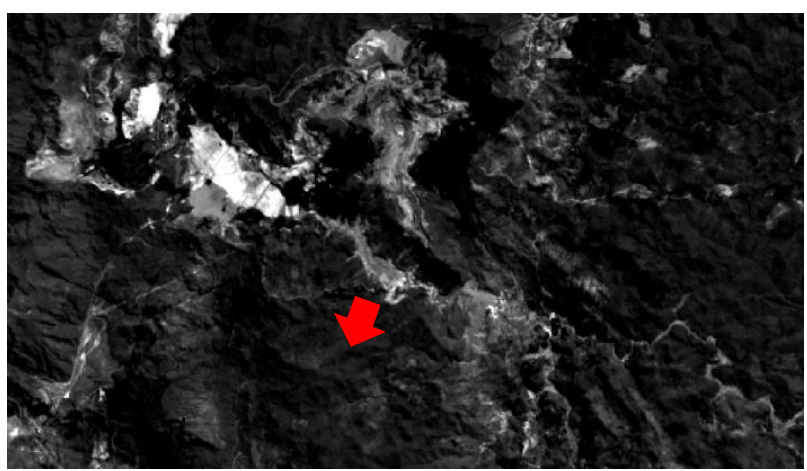

Figura 2: Subtração Simples de Bandas com as bandas do canal do verde (novembro de 2016 - outubro de 2015).

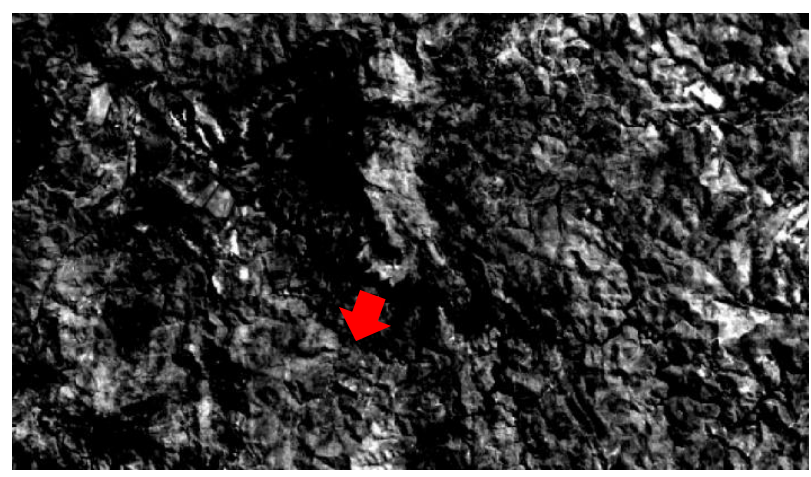

Figura 4: Subtração Simples de Bandas com as bandas do canal do infravermelho próximo (novembro de 2016 - outubro de 2015).

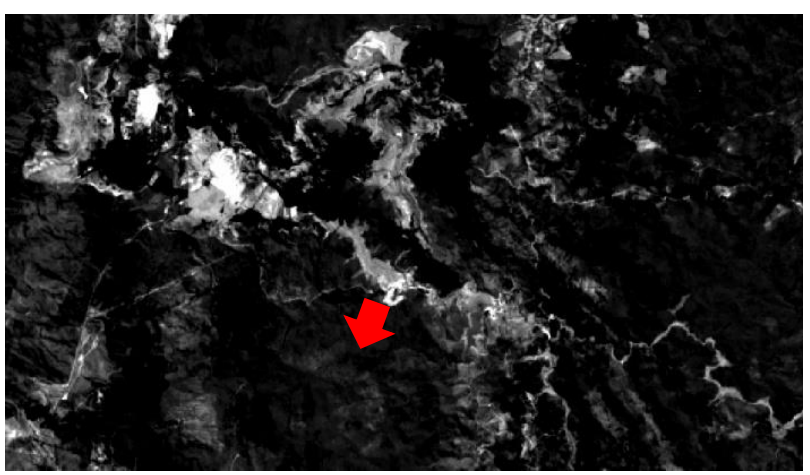

Figura 3: Subtração Simples de Bandas com as bandas do canal do vermelho (novembro de 2016 - outubro de 2015).

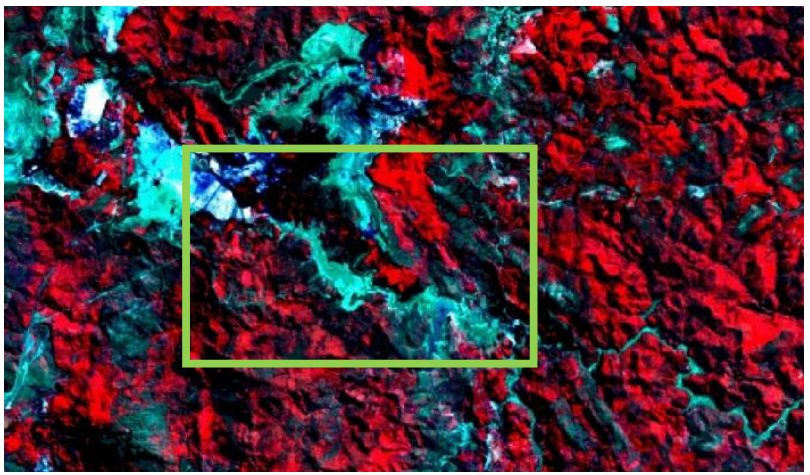

Figura 5: Composição colorida falsa cor (345BGR) das imagens resultantes.

Nas figuras 2 e 3 podemos identificar que as áreas que apresentaram mudança estão representadas pelos pixels de maior intensidade, portanto os mais claros. Isto se deve porque áreas com resposta espectral semelhante ao solo exposto são bem refletidas para este canal. As setas nas figuras indicam a localização 


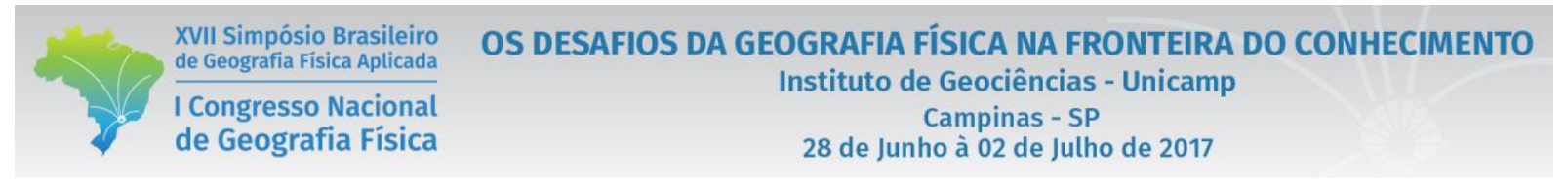

das extremidades do barramento onde a lama teria extrapolado seus limites seu rompimento. As áreas que apresentaram intermediários nível de cinza são aquelas que não obtiveram abruptas alterações.

A imagem resultante da subtração para o canal do infravermelho próximo apresentou as mudanças na área da barragem com pixels de valores mais baixos ou nulos (0), não tendo boa diferenciação com as áreas limítrofes. Áreas de vegetação densa e arbustiva, encontradas no entorno, assim como corpos d'água tendem a absorver muito da energia eletromagnética nessa banda.

A figura 5 apresenta a composição colorida falsa cor (345BGR) com as imagens resultantes da operação em que as tonalidades de verde mais claro mostram a expansão do sedimento da barragem. As manchas esverdeadas acompanham o caminho do sedimento. Já as manchas avermelhadas mostram as áreas que não sofreram com alterações perceptíveis para nesse período.

As imagens resultantes das Análises de Componentes Principais (CP2) são apresentadas pelas figuras 6, 7 e 8 com a composição colorida falsa cor (BGR) dessas imagens apresentadas na figura 9.

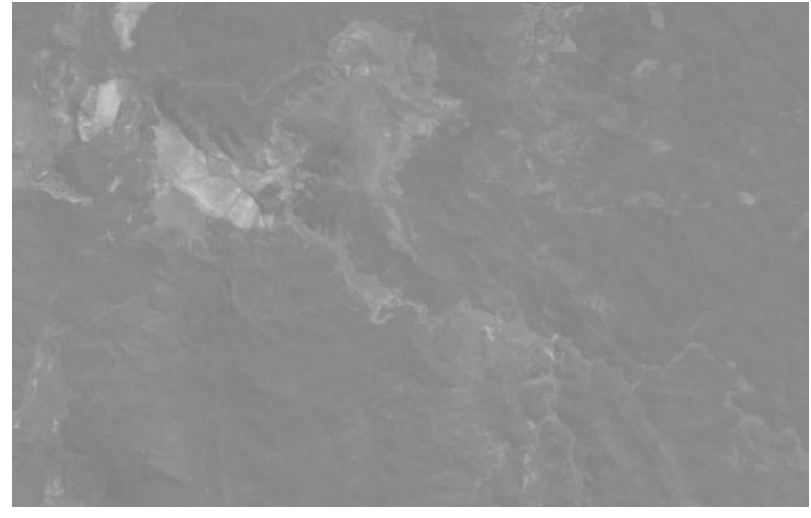

Figura 6: Análise dos Componentes Principais (CP2) para as bandas do canal do verde.

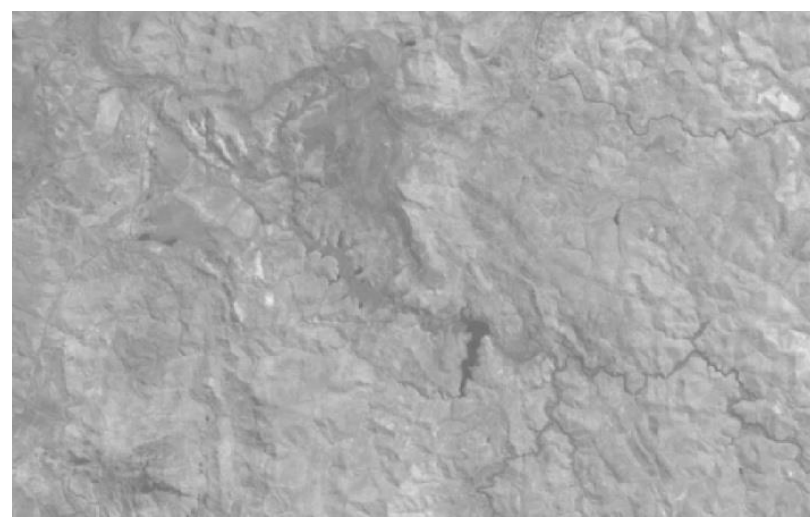

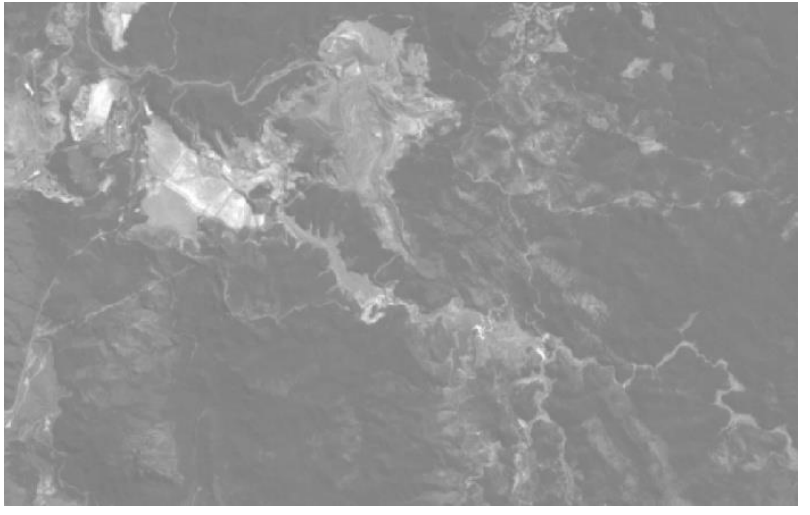

Figura 7: Análise dos Componentes Principais (CP2) para as bandas do canal do vermelho.

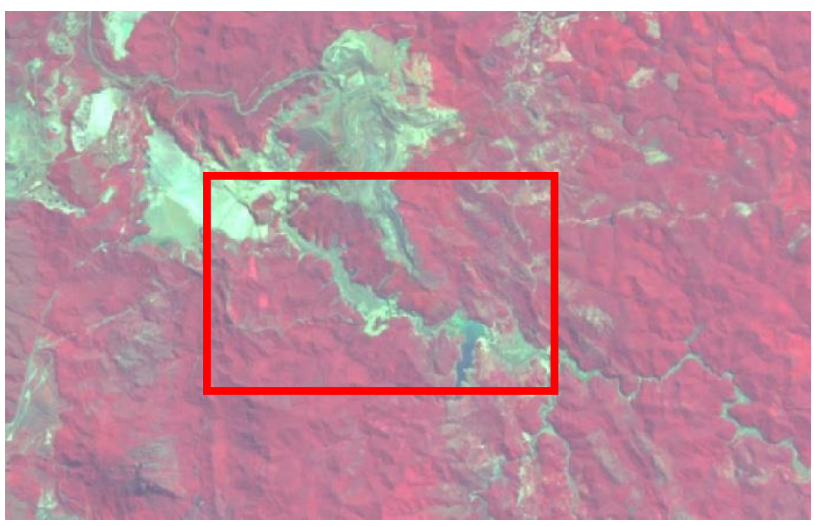


Figura 8: Análise dos Componentes Principais (CP2) para as bandas do canal do Infravermelho próximo.

Figura 9: Composição colorida falsa cor (BGR) com os resultados das Análises dos Componentes Principais.

Assim como as imagens resultantes das subtrações, o resultado com maior contraste da expansão foi apresentado pelo componente principal do canal do vermelho (figura 7). $\mathrm{Da}$ mesma forma que o infravermelho próximo (figura 8) apresentou pixels de valores médios que confundem com as áreas que não sofreram as alterações dispostas a serem verificadas.

$\mathrm{Na}$ composição colorida da Análise dos Componentes Principais (figura 9) as áreas de ciano e verde com as tonalidades mais claras representam as áreas de maior modificação temporal. A falsa cor verde foi associada à banda do vermelho, portanto as novas informações obtidas linearmente pela Análise dos Componentes Principais indicaram grande variação temporal visível nessa cor.

\section{Considerações finais}

Tanto a Subtração Simples de Bandas quanto a Análise de Componentes Principais se mostraram úteis e eficazes para identificação da expansão da lama no entorno na barragem de Santarém após seu rompimento. Elas podem ser utilizadas tanto como técnicas complementares como singulares dependendo do estudo. Para esse trabalho elas serviram para rápida visualização do acontecido. Entretanto, a expansão dos sedimentos pôde ser identificada enaltecendo a eficiência na utilização de imagens orbitais para esse fim. Essa é uma das pesquisas iniciais de um projeto maior que pretende verificar os impactos causados pelo rompimento da barragem em partes da bacia do Rio Doce utilizando técnicas de geoprocessamento e sensoriamento remoto. Estudos como esse são importantes para que mais trabalhos discutam a cerca do acontecido e que novas ferramentas para planejamento e gestão sejam fornecidas e aprimoradas.

As imagens multiespectrais do sensor OLI (Landsat 8) utilizadas nesse trabalho possuem $30 \mathrm{~m}$ de resolução espacial. Apesar de seu fácil acesso foi apresentado dificuldade na identificação de algumas feições limítrofes do barramento. Para futuros trabalhos sugere-se a utilização de imagens com melhor resolução espacial para que os limites dos rejeitos e da barragem tenho maior acurácia em sua identificação.

\section{Referências Bibliográficas}

ALBERTI, G. A.; VICTORINO, H. da S. Detecção da expansão da barragem de rejeitos Maravilhas II (MG) por Subtração Simples de Bandas e Análise de Componentes Principais. Anais XVII Simpósio Brasileiro de Sensoriamento Remoto - SBSR, João PessoaPB, Brasil, 25 a 29 de abril de 2015, INPE. Disponível em: 


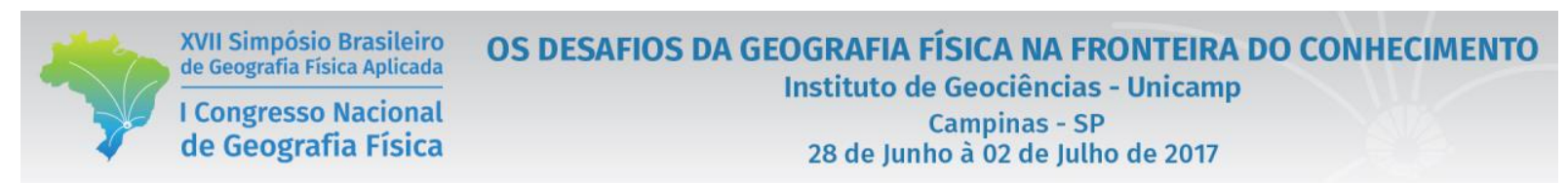

$<$ http://www.dsr.inpe.br/sbsr2015/files/p0955.pd

FARIA, M. Barragens de rejeito já causaram f>. Acesso em 31 de jan. de 2017.

CHAVEZ Jr., P. S. An improved dark-object subtraction technique for atmospheric scattering correction of multispectral data. Flagstaff, Arizona. Remote Sensing of Environment, 1988. V. 24, p. 459-479.

CHAVEZ Jr, P.S.; MAC KINNON, D.J. Automatic detection of vegetation changes in South United States using remotely sensed images. Photogrametric Engineering \& Remote Sensing, v.60, n.5, p.571-583, 1994.

CPRM. Monitoramento Especial do Rio Doce. CPRM: Belo Horizonte, 2015. Disponível em: <http://www.cprm.gov.br/publique/Hidrologia/E ventos-Criticos/Monitoramento-Especial-doRio-Doce-4057.html>. Acesso em 14 de março de 2016.

ESPÓSITO, T. de J. Metodologia probabilística e observacional aplicada a barragens de rejeitos construídas por aterro hidráulico. 363f. Tese (Doutorado em Geotecnia) - Universidade Federal de Brasília, Brasília, 2000.

\section{FUNDAÇÃO ESTADUAL DO MEIO AMBIENTE. Inventário Estadual de Barragens do ano de 2014. Belo Horizonte: Feam, 2014. Disponível em: <http://www.feam.br/images/stories/2015/DECL ARACOES_AMBIENTAIS/GESTAO_DE_BA RRAGENS/correo_inventrio\%20de\%20barragen s_2014_final.pdf>. Acesso em 30 de maio de 2016.}

IBAMA. Laudo Técnico Preliminar: Impactos ambientais decorrentes do desastre envolvendo o rompimento da barragem de Fundão, em Mariana, Minas Gerais. Instituto Brasileiro do Meio Ambiente e dos Recursos Renováveis. Diretoria de Proteção Ambiental DIPRO e Coordenação Geral de Emergências Ambientais - CGEMA. Brasília, 2015. Disponível em: <http://www.ibama.gov.br/phocadownload/notic ias_ambientais/laudo_tecnico_preliminar.pdf $>$. Acesso em 14 de mar. de 2016. 
INMET. Normais climatológicas do Brasil

1961-1990. Instituto Nacional de Meteorologia: Brasília, 2016.

Disponível

em

$<$ http://www.inmet.gov.br/portal/index.php?r=cli ma/normaisclimatologicas>. Acesso em 25 de jun. de 2016.

PORTAL DO BRASIL. Setor mineral representa 4\% do PIB brasileiro. Brasília, 2014. Brasília, 2014. Disponível em <http://www.brasil.gov.br/infraestrutura/2014/12 /setor-mineral-representa-4-por-cento-do-pibbrasileiro>. Acesso em 28 de mar. de 2016.

SAUSEN, T. M.; LACRUZ, M. S. P. Org. Sensoriamento remoto para desastres. São Paulo: Oficina de textos, 2015.

SUPRAM ZM. Parecer técnico supram - zm $\mathbf{N}^{\mathbf{0}}$ : 0201538/2011. Secretaria de Estado de Meio Ambiente e Desenvolvimento Sustentável: Belo Horizonte, 2014. In. GIAIA. Disponível em $<$ http://giaia.eco.br/wpcontent/uploads/2015/11/SUPRAM-2011adendo.pdf $>$. Acesso em 30 de maio de 2016.

USGS. Landsat Missions: Using the USGS Landsat8 Product. U.S. Department of the
Interior; U.S. Geological Survey - NASA, 2015.

Disponível

em $<$ http://landsat.usgs.gov/Landsat8_Using_Produc t.php>. Acesso em 28 de maio de 2016.

VARELlA, C. A. A. Análise de componentes principais. Seropédica: Rio de Janeiro, 2008. Disponível em: $<$ http://www.ufrrj.br/institutos/it/deng/varella/Do wnloads/multivariada\%20aplicada\%20as\%20cie ncias\%20agrarias/Aulas/analise\%20de\%20comp onentes\%20principais.pdf>. Acesso em 31 de jan. de 2017. 